\title{
HTLV-I (Human T - cell lymphotropic virus), algo que decir?
}

PATRICIA VÁSQUEZ T.

\section{HTLV-I (Human T-cell lymphotropic virus): something to say?}

Human T cell Lymphotropic Virus-I is associated to several pathological conditions being spastic paraparesia and adult T-cell leukemia/lymphoma the most relevant. This infection hasn't specific treatment and different therapeutic assays have been intended for its management. Scientific literature is reviewed summarizing most updated publications about treatment assays.

Key words: Human T cell Lymphotropic Virus-I; Treatment; T-cell lymphoma; T-cell leukemia

Los retrovirus fueron los primeros virus de los que se tuvo conocimiento; sin embargo, por más de un siglo sólo se encontraron en animales, usualmente asociados a leucemia o linfomas ${ }^{1}$. En 1950, se promovió su investigación especialmente en un programa del National Cancer Institute ${ }^{2}$.

El virus linfotrópico T humano tipo I se clasifica en la familia de los Retroviridae basándose en la estructura del genoma y la secuencia nucleotídica, y en la subfamilia de Oncoviridae por su patogenicidad.

En 1980, Poiesz y colaboradores aislaron partículas de retrovirus de células frescas de un paciente con linfoma T cutáneo. En 1981, Hinuma y colaboradores también aislaron partículas de retrovirus en líneas celulares de pacientes japoneses adultos con leucemia de células T. Posteriores trabajos demostraron la asociación de este virus con la leucemia/linfoma de células $\mathrm{T}$ del adulto. La relación con paraparesia espástica se atribuye a los trabajos de Gessain en $1985^{3}$.

Son varias otras patologías las que actualmente se asocian con este virus como uveitis, epiescleritis, artritis ${ }^{4}$.

En Chile, se asoció a paraparesia espástica en $1989^{5}$ y en 1991 se describió por primera vez en donantes de bancos de sangre ${ }^{6}$.

$\mathrm{Su}$ ciclo biológico tanto como el impacto en salud pública difieren mucho del VIH, por lo que la epidemia de SIDA y sus devastadoras conse- cuencias han dejado atrás la investigación y enfoque terapéutico del HTLV-I.

La infección por virus HTLV-I se caracteriza por estar distribuida en regiones geográficas definidas que aparentemente no se relacionan, aunque hay amplios estudios de migraciones que podrían explicar un pasado común. Es endémico en Japón, Caribe, África, América del Sur e Islas Seychelles y es más prevalente en mujeres y en la edad media de la vida. Hay cerca de 20 millones de infectados en el mundo y desarrollan alguna enfermedad relacionada entre 3 y $5 \%$ de los infectados.

\section{Epidemiología}

Está basada en la prevalencia de donantes de sangre; el diagnóstico serológico se hace habitualmente con un método de ELISA y luego puede ser confirmado con Westernblot o IFI.

Sero prevalencia. En Chile, Santiago (Hospital Del Salvador) es de 0,3\%. En E.U.A., Los Angeles: 0,1\%, en Washington: 0,06\%. En Japón: 0 a $20 \%$ y en Jamaica: $6 \%$.

$\mathrm{Si}$ lo comparamos con otras enfermedades transmisibles por transfusión sanguínea, ese mismo año en el mismo banco de sangre en nuestro país, podemos observar que esta prevalencia lo convierte en una patología bastante importante: Chagas 0,6\%; VIH 0,075\%; hepatitis B 0,05\%; hepatitis $\mathrm{C} 0,25 \%$.

\footnotetext{
* Unidad de Infectología. Servicio de Medicina Interna. Hospital San Juan de Dios

E-mail: ptorielo@rdc.cl
} 


\section{Mecanismos de transmisión}

Se produce principalmente por células que contienen el provirus y no por viriones libres. La transmisión sexual es poco eficiente en general y por ser un virus adosado a células es 100 veces más eficiente su transmisión de hombre a mujer que a la inversa. La transmisión vertical es principalmente por leche materna. Hay estudios que muestran 3\% de hijos seropositivos para HTLV-I de madres portadoras que le dan lactancia artificial y $38 \%$ de seropositividad en los hijos que reciben lactancia materna. Transmisión por sangre: debe ser sangre y hemoderivados que contengan elementos celulares. Un estudio centinela en Japón mostró que $68 \%$ de los receptores de sangre, glóbulos rojos y plaquetas seroconvirtieron y tan sólo 0 a $1 \%$ de los receptores de plasma. Disminuye mucho la transmisión al usar glóbulos rojos desleucocitados.

Hay casos descritos de transmisión por compartir jeringas en personas drogadictas.

Características. Los virus aislados de diferentes partes del mundo muestran una homología de $97 \%$ o más a diferencia de lo que ocurre con el VIH. El genoma proviral tiene los genes gag, pol y env; in vitro tiene gran tropismo por células $\mathrm{T}$ pero no tiene efecto citopático. Se descubrieron además genes reguladores tax y rex.

Gen tax: transforma las células T inhibiendo la apoptosis y promueve la proliferación celular, desregula la expresión celular de los genes y otras acciones.

El mecanismo de enfermedad neurológica es más oscuro y sería producido por estímulo en la producción de IL-15 y FNT (teoría desmielinizante y citotoxicidad producida por el virus).

\section{Cuadros clínicos}

\section{Leucemia /linfoma de células $\mathbf{T}$ del adulto:} hay cuatro formas clínicas bastante definidas. En general la neoplasia se desarrolla en cerca del 5\% de los infectados y con una latencia de alrededor de 30 años desde a la infección viral. Además se asocia un cuadro de inmunodeficiencia celular que permite la aparición de infecciones oportunistas como Pneumocystis jiroveci (ex carinii), meningitis por Cryptococcus sp y, en zonas tropicales, estrongiloidosis.

\section{Formas clínicas}

- Leucemia subaguda de curso agresivo con presencia de células pleomórficas de estirpe T madura, con hipercalcemia, organomegalia y lesiones cutáneas.

- Linfoma de curso agresivo pero sin evidencia de cuadro leucémico.

- Crónica, caracterizada por lesiones cutáneas y linfocitosis T. Suele mantenerse estable durante meses o años.

- Smoldering o latente, asintomática o con algunas manifestaciones cutáneas y/o pulmonares.

Paraparesia espástica: Se caracteriza por ser una enfermedad crónica desmielinizante que afecta la médula espinal y la sustancia blanca del SNC, produciendo un síndrome paretoespástico de extremidades inferiores, además de compromiso autonómico. Se asocia en más del $50 \%$ con síndrome de sica. Actualmente hay en estudio paraparesias de iguales características, seronegativas, pero con presencia de secuencias de tax en linfocitos periféricos.

La latencia para el compromiso neurológico postransfusional es de 3 a 4 años aunque hay casos más precoces. En algunos casos se produce compromiso de funciones superiores.

Prevalencia nacional: 2 cada 100.000 habitantes. Se distribuye por igual en todo Chile. En nuestro país los casos de paraparesia espástica están centralizados en el Servicio de Neurología del Hospital Del Salvador. Se atienden alrededor de 200 pacientes. El serotipo nacional pertenece al subgrupo Transcontinental de la cepa Cosmopolita.

Un $35 \%$ tiene antecedentes transfusionales o de cirugía mayor, a diferencia de paraparesias espásticas de otra etiología.

La coexistencia de cuadro leucémico y neurológico es infrecuente. ${ }^{7}$

\section{Tratamiento}

Tanto en la leucemia / linfoma de células T del adulto como en la paraparesia espástica los resultados de variados tratamientos son ineficaces.

A continuación se muestran revisiones de nuevas opciones terapéuticas.

\section{Ensayos terapéuticos para leucemia /linfoma $\mathbf{T}$ del adulto.}

Se basan en los siguientes antecedentes:

- Baja presencia de viriones.

- Alta carga de ADN proviral en células periféricas mononucleares en pacientes con enfermedad activa.

- Integración clonal del HTLV-I a las células tumorales. 
- Pronóstico ominoso de enfermedad subaguda (5 a 13 meses desde el diagnóstico).

- Refractariedad a quimioterapias habituales.

- Los linfocitos malignos son células T CD4 activadas con aumento de la expresión de cadena alfa del receptor para IL-2.

Combinación de interferón alfa y zidovudina (N Engl J Med 1995; 332: 26). Fueron 19 pacientes con forma aguda o linfomatosa; 7 con recaída o falla a quimioterapia; 4 con coinfección VIH, 2 con mielopatía asociada. Recibieron un regimen de AZT $200 \mathrm{mg} 5$ veces al día + interferón alfa 5-10 millones sc. Resultados: $58 \%$ tuvieron buena respuesta (11 pacientes), $26 \%$ de pacientes con remisión completa ( 5 pacientes). De los 5 pacientes con remisión completa, 2 tenían VIH y fallecieron por esta causa. Los 3 que quedaron, sobrevivieron 15, 16 y 63 meses respectivamente. En 7 pacientes con respuesta parcial, sólo 2 murieron sin evidencia de enfermedad. La sobrevida media de los 11 pacientes fue de 17 meses.

Tratamiento con anticuerpos monoclonales dirigidos a receptor de $\mathrm{IL}-2$ + interferon alfa + AZT. (Curr Treat Options Oncol 2001 Aug; 2 (4)) Sólo un pequeño porcentaje presentó remisión más prolongada.

Sensibilidad a 5 inhibidores de transcriptasa reversa análogos de nucleósidos (J Infect Dis. 2001 Aug 15). Referencia: VIH salvaje y resistente. Se demostró alta resistencia de HTLV-I a 3TC (lamivudina).

Uso de deoxycoformicina para quimioterapia en LLCT, (Int J Hematol, 2003, Feb): no demostró buenos resultados.

Trasplante alogénico de células progenitoras. (Br J Haematol 2003; 120: 3049). Se reclutaron 11 pacientes: 6 agudos, 4 linfomas, 1 crónico. El condicionamiento fue convencional en 9 y de intensidad reducida en 2. Cinco pacientes desarrollaron GVHD (enfermedad injerto versus huésped) aguda y 3 de 8 que sobrevivieron más de 100 días desarrollaron GVHD crónica. Hubo remisión completa en 10 que sobrevivieron más de 30 días. Fallecieron 7 de complicaciones relacionadas con el trasplante ( 2 por GVHD aguda y 3 por GVHD crónica). El promedio estimado de sobrevida a 1 año fue de $54 \%$, el promedio estimado de período libre de enfermedad: de $45 \%$. Actualmente se reportan 4 pacientes vivos por más de 25 meses, sin enfermedad. El efecto GVL (injerto versus leucemia) es fundamental y ninguno tuvo GVHD.

Leucemia/linfoma T del adulto en Chile. ${ }^{7}$

Contempló 26 pacientes: Las manifestaciones clínicas son similares a las descritas en otros países. La mayoría de los pacientes eran de Santiago y se incluyó igual número de mujeres y hombres. Como antecedentes, 4 habían sido transfundidos. Dieciocho pacientes se presentaron con la forma aguda. En 8 pacientes se presentó en forma concomitante un cuadro neurológico. Destacable fue la alta incidencia de seropositividad familiar (63\%). Como tratamiento se empleó distintos esquemas de quimioterapia (CHOPP, C- MOPP, etc.); 4 pacientes con la forma aguda no recibieron terapia por su pronóstico ominoso, la sobrevida de esta forma de presentación fue de 4 meses.

\section{Paraparesia espástica: Enfoques terapéuticos}

Corticosteroides. Se han usado en varias formas como prednisona, pulsos de metilprednisolona y dexametasona, con efectos de mejoría transitoria. Reporte que fuera recientemente publicado en Rev Neurol 2000 Jul; 31(1): 1-15.

Danazol. Andrógeno que tendría un efecto inmunomodulador: hay algunos reportes de mejoría transitoria de la vejiga neurogénica.

Pentoxifilina. Antiagregante que disminuye la producción de interferon alfa, no tiene eficacia.

Lamivudina. (J Virol 1999 Dec; 73(12)) Se mide ADN proviral en células mononucleares de sangre periférica y su disminución después del tratamiento. (5 pacientes).

Terapia antiretroviral. (Virus Res 2001 Oct 30; 78 (1-2). Dos pacientes con TSPP tratados con AZT/3TC. Un de ellos sin respuesta clínica en 1 año de tratamiento pero con reducción del ADN proviral.

Estos trabajos apoyarían que, a pesar de la expansión clonal como mecanismo de replicación, también hay replicación por transcripción reversa

Vacuna anti HTLV-I. (Vaccine. 2003 jun 20; 21 (21-22): Basado en que los linfocitos $\mathrm{T}$ citotóxicos son fundamentales en la eliminación del virus y la estabilidad del HTLV-I, se propone desarrollar una vacuna peptídica derivada de la proteína reguladora Tax del HTLV-I. Estudio efectuado en ratas.

\section{Conclusiones}

Las tentativas de tratamiento específico para las patologías asociadas al virus HTLV-I son bastante desalentadoras.

En la paraparesia espástica hay algunos beneficios del uso de corticosteroides sobre todo en la forma de pulsos de metilprednisolona en etapas agudas. El uso de antiretrovirales se reduce bási- 
camente a zidovudina ya que a lamivudina sería resistente. Los trabajos no son concluyentes.

En la leucemia /linfoma de células T, en su forma más agresiva, la quimioterapia habitual ha demostrado ser inefectiva. El trabajo reciente que plantea transplante alogénico de médula parece ser por el momento la terapia más promisoria.

La prevención se convierte en un pilar fundamental al no contar con terapia efectiva al momento actual. Se debe orientar a los donantes seropositivos para lo siguiente: No donar sangre, semen ni órganos, no amamantar a sus hijos, usar preservativos en las relaciones sexuales y si se planea tener familia, sólo dejar el preservativo en los períodos fértiles En cada país se debe evaluar la posibilidad de realizar el tamizaje en bancos de sangre según las prevalencias de cada lugar y es recomendable evaluar el estudio rutinario previo a efectuar trasplantes de órganos.

\section{Resumen}

El virus HTLV-I se asocia a varias patologías siendo las más relevantes la paraparesia espástica y la leucemia/linfoma de células T del adulto. No tiene tratamiento específico y se han intentado varios esquemas terapéuticos para su manejo. Se revisa la literatura presentando los trabajos más actualizados en relación a la terapia.

\section{Bibliografía}

1.- Gross L. Oncogenic Viruses, 3rd edición. Oxford: Pergamon, 1983.

2.- Gallo R C. Virus hunting AIDS, cancer and the human retroviruses: a Story of Scientific Discovery. New York : Basic Books, 1991.

3.- Gallo R C. Human retroviruses after 20 years: a perspective from the past and prospects for their future control. Immunol Rev 2002; 185: 236-65.

4.- Mochizuki M, Tajima K, Watanbe T, Yamaguchi K. Human $\mathrm{T}$ lymphotropic virus type I uveitis. $\mathrm{Br} \mathrm{J}$ Ophtalmol 1994; 78: 149-54.

5.- Cartier L, Mora C, Araya F, Castillo J, Verdugo R, Miller M. HTLV-I positive spastic paraparesis in a temperate zone (letter). Lancet 1989; 1: 556.

6.- Vásquez P, Sánchez G, Volante C et al. Human T Lymphotropic Virus Type I: New risk for Chilean population (letter). Blood 1991 Aug; 78 (3).

7.- Cabrera M E. Leucemia/linfoma T del adulto en Chile. Rev Méd Chile 1999; 127: 935-44.

8.- Cartier R L, Araya D F, Castillo J et al. Retrovirus HTLV-I en Chile: estudio de 140 enfermos neurológicos. Rev Méd Chile 1990; 118: 662-8.

9.- Ramos J, Correa G. Mielopatia associada ao virus linfotropico humano de células T do tipo 1 (HTLVI), Rev Soc Bras Med Trop 2002; 35 (4): 377-94.

10.- Carneiro-Proietti B, Ramos J, Catala B et al: Infeccao e doenca pelos vírus linfotrópicos humanos de células T (HTLVI/II) no Brasil. Rev Soc Bras Med Trop 2002; 35: 499-508. 